\title{
Наследование хозяйственно-ценных признаков у гибридов льна культурного
}

Никитинская T.B. ${ }^{1 *}$, н.с.; Кубрак С.В. ${ }^{1}$, к.б.н., с.н.с.; Титок В.В. ${ }^{2}$, чл.-корр., д.б.н., директор.

${ }^{1}$ Институт генетики и ичитологии НАН Беларуси, Минск, Республика Белаpycb;

${ }^{2}$ Центральный ботанический сад НАН Беларуси, Минск, Республика Беларусь. *e-mail: Nikitinskaja@yandex.ru

Проведен анализ наследования хозяйственно-иенных признаков у гибридов льна культурного. Установлено более частое проявление гетерозиса по признаку «масса 1000 семян». Характер наследование этого признака у гибридов $F_{1}$ и $F_{2}$ был достаточно стабильным. Признаки техническая длина стебля и содержание волокна в поколении $F_{1}$ чаще наследовались по типу доминирования и сверхдоминирования в сторону уменьшения признака, в $F_{2}$ поколении - разнонаправленный характер наследования. Содержание масла наследовалось по типу промежуточного наследования и сверхдоминирования в сторону уменьшения признаков.

Ключевые слова: лен культурный, наследование хозяйственно-иенных признаков, гетерозис.

\section{Inheritance of economically valuable traits in flax hybrids}

Nikitinskaya T.V. ${ }^{l}$, Researcher, Kubrak S.V. ${ }^{1}$, PhD, Senior Researcher, Titok V.V. ${ }^{2}$, Corresponding Member, Doctor of Science, Director.

${ }^{1}$ Institute of Genetics and Cytology of NAS of Belarus", Minsk, Republic of Belarus, ${ }^{2}$ Central Botani-cal Garden of NAS of Belarus, Minsk, Republic of Belarus.

E-mail: Nikitinskaja@yandex.ru

The analysis of inheritance of economically valuable traits in hybrids of Linum usitatissimum L. is carried out. A more frequent manifestation of heterosis on the basis of the "weight of 1000 seeds" has been established. The inheritance of this trait in hybrids $F_{1}$ and $F_{2}$ was quite stable. The characteristics of the technical stem length and fiber content in the $F_{1}$ generation were more often inherited by the type of dominance and overdomination towards a decrease in the sign, in the $F_{2}$ generation - the multidirectional nature of inheritance. The oil content was of the type of intermedi-ate inheritance and overdomination in the direction of decreasing signs.

Keywords: Linum usitatissimum L., inheritance of economically valuable traits, heterosis.

Для повышения продуктивности, обогащения и расширения генети- 
ческого пула льна культурного были проведены скрещивания разных подвидов льна, с последующим анализом наследования хозяйственно-ценных признаков.

Наследование оценивали по значениям истинного гетерозиса и степени доминирования. Исследовали следующие признаки: масса 1000 семян, техническая длина стебля, содержание волокна, содержание масла. В работе использовали 23 гибрида поколения $\mathrm{F}_{1}$ и $\mathrm{F}_{2}$, полученные в системе трех топкроссных скрещиваний. Признаки оценивали по отношению к родительским формам разных подвидов льна.

Значение истинного гетерозиса (ИГ) оценивали как процент превышения значения признака гибрида $\mathrm{F}_{1}$ или $\mathrm{F}_{2}\left(\mathrm{X}_{\mathrm{F} 1}\right.$ или $\left.\mathrm{X}_{\mathrm{F} 2}\right)$ над значением признака лучшего родителя $\left(\mathrm{X}_{\mathrm{Pmax}}\right)$, т.е. ИГ $=\frac{\mathrm{X}_{\mathrm{F}_{1}}-\mathrm{X}_{\mathrm{P}_{\max }}}{\mathrm{X}_{\mathrm{P}_{\max }}} \times 100 \%[1]$. Степень доминантности - как отношение разности значений признаков гибрида ( $\mathrm{F}_{1}$ или $\mathrm{F}_{2}$ ) и среднего арифметического родительских форм к половине разности значений родительских форм, взятой по абсолютной величине [2-3], т.е. $\mathrm{hp}=\frac{\mathrm{X}_{\mathrm{F}_{1}}-\frac{\mathrm{X}_{\mathrm{P} 1}+\mathrm{X}_{\mathrm{P} 2}}{2}}{\frac{1}{2}\left|\mathrm{X}_{\mathrm{P} 1}-\mathrm{X}_{\mathrm{P} 2}\right|}$, где $\mathrm{X}_{\mathrm{F} 1}\left(\mathrm{X}_{\mathrm{F} 2}\right), \mathrm{X}_{\mathrm{P} 1}, \mathrm{X}_{\mathrm{P} 2}-$ средние значения признаков $\mathrm{F}_{1}\left(\mathrm{~F}_{2}\right)$, Р1 и $\mathrm{P} 2$ соответственно.

Согласно полученным результатам, по признаку «масса 1000 семян» у гибридов $\mathrm{F}_{1}$ превосходство лучшего родителя наблюдалось у 9 образцов. Максимальные значения истинного гетерозиса наблюдались у двух гибридов $\mathrm{F}_{1}$ Блакит $\times \mathrm{K}-4821$ (22,92 \%) и Ariane $\times \mathrm{K}-4821$ (22,72 \%), полученных при скрещивании образцов льна-долгунца и льна растрескивающегося. У гибридов $\mathrm{F}_{2}$ положительные значения истинного гетерозиса выявлены у 8 образцов. Максимальным значением превосходства лучшего родителя характеризовался гибрид $\mathrm{F}_{2}$ Блакит $\times$ Cree $(8,44 \%)$. При этом у трех генотипов (Блакит $\times$ Cree, Блакит $\times$ Ручеек и Славный $82 \times$ К-4821) положительный истинный гетерозис наблюдался как в $\mathrm{F}_{1}$, так и в $\mathrm{F}_{2}$ поколениях (табл. 1).

По признаку «техническая длина стебля» ни один гибрид $\mathrm{F}_{1}$ не превзошел лучшего родителя. У трех гибридов $\mathrm{F}_{2}$ значения истинного гетерозиса были положительными. Максимальное значение истинного гетерозиса по признаку наблюдалось у гибрида $F_{2}$ Славный $82 \times$ Endress Olajlen и составило $2,68 \%$.

По содержанию волокна положительные значения истинного гетерозиса наблюдались у гибрида $\mathrm{F}_{1}$ Славный $82 \times$ Endress Olajlen $(1,34 \%)$ и трех гибридов $F_{2}$ Блакит $\times$ Ручеек $(9,44 \%)$, Славный $82 \times$ Raluca $(2,92 \%)$, Славный $82 \times$ Ocean $(5,28 \%)$, полученных при скрещивании генотипов льна-долгунца с генотипами льна-кудряша и льна крупносемянного.

По содержанию масла превосходство лучшего родителя наблюдалось у двух гибридных форм $\mathrm{F}_{2}$ Блакит $\times$ Norlin $(2,63 \%)$ и Ariane $\times$ Cree $(4,12 \%)$, полученных при скрещивании линий льна-долгунца и льна-межеумка. 


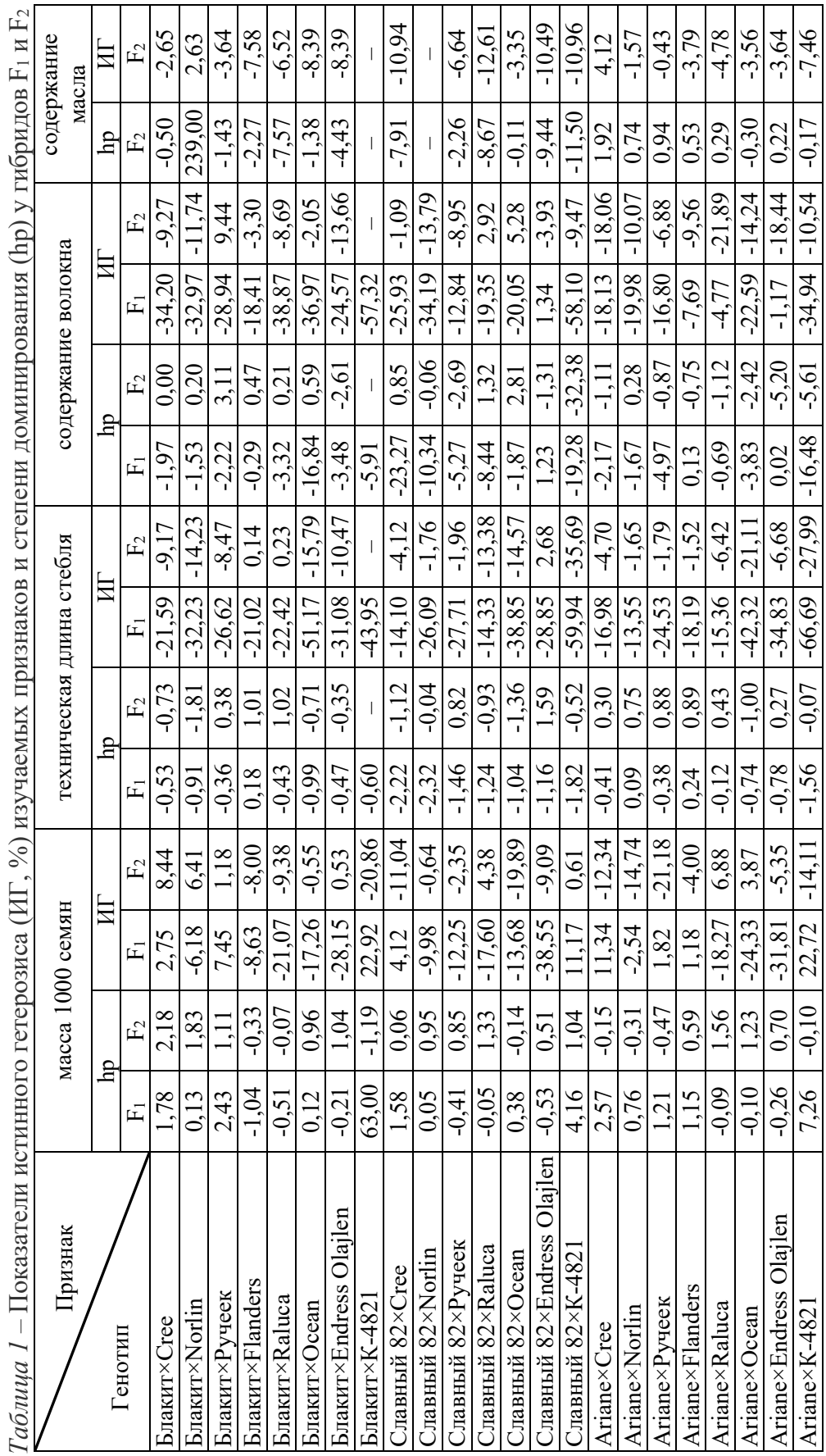


Наряду с изучением значений истинного гетерозиса, проведен анализ степени доминирования изучаемых признаков.

По признаку «масса 1000 семян» у 43,5 \% гибридов $\mathrm{F}_{1}$ наследование изучаемого признака было по типу промежуточного наследования, 43,5 \% гибридов проявляли доминирование и сверхдоминирование в сторону увеличения признака, остальные гибриды $\mathrm{F}_{1}$ демонстрировали доминирование и сверхдоминирование в сторону уменьшения признака (табл. 2).

Таблица 2 - Проявление доминирования (*) по изучаемым признакам у гибридов $\mathrm{F}_{1}$ и $\mathrm{F}_{2}, \%$

\begin{tabular}{|l|l|c|c|c|c|c|}
\hline \multicolumn{1}{|c|}{ Признак } & $\begin{array}{c}\text { Год } \\
\text { (число ги- } \\
\text { бридов) }\end{array}$ & $\mathrm{hp}<-1$ & $-1 \leq \mathrm{hp}<-0,5$ & $-0,5 \leq \mathrm{hp} \leq+0,5$ & $+0,5<\mathrm{hp} \leq+1$ & $+1<\mathrm{hp}$ \\
\hline \multirow{2}{*}{ масса 1000 семян } & $\mathrm{F}_{1}(23)$ & 4,35 & 8,70 & 43,47 & 4,35 & 39,13 \\
\cline { 2 - 8 } & $\mathrm{F}_{2}(23)$ & 4,35 & 0 & 34,78 & 26,09 & 34,78 \\
\hline $\begin{array}{l}\text { техническая длина } \\
\text { стебля }\end{array}$ & $\mathrm{F}_{1}(23)$ & 34,78 & 26,09 & 39,13 & 0 & 0 \\
\cline { 2 - 7 } $\begin{array}{l}\text { содержание } \\
\text { волокна }\end{array}$ & $\mathrm{F}_{2}(22)$ & 18,18 & 13,64 & 31,82 & 22,72 & 13,64 \\
\hline содержание масла & $\mathrm{F}_{2}(22)$ & 78,26 & 4,35 & 13,04 & 0 & 4,35 \\
\hline
\end{tabular}

Примечание * - $<\mathrm{hp}<-1$ - отрицательное сверхдоминирование (отрицательный гетерозис); $-1 \leq \mathrm{hp}<-0,5$ - отрицательное доминирование; $-0,5 \leq \mathrm{hp} \leq+0,5$ - промежуточное наследование; $+0,5<\mathrm{hp} \leq+1$ - положительное доминирование; $+1<\mathrm{hp}<+\infty$ - положительное сверхдоминирование (положительный гетерозис) [3].

У большинства гибридов $\mathrm{F}_{2}$ данный признак наследовался по типу доминирования и сверхдоминирования в сторону увеличения признака $(60,87 \%)$. Промежуточный характер наследования продемонстрировали $34,8 \%$ гибридов $\mathrm{F}_{2}, 4,35 \%$ - сверхдоминирование в сторону уменьшения признака. Анализ проявления признака по генотипам показал, что 3 гибрида имели положительное сверхдоминирование, как в первом поколении, так и во втором (табл. 1).

По признаку «техническая длина стебля» в первом поколении у 60,9 \% гибридов наблюдалось доминирование и сверхдоминирование в сторону уменьшения признака, у более $39 \%$ - промежуточный характер наследования изучаемого признака. У гибридов $\mathrm{F}_{2}$ наблюдался разнонаправленный характер наследования признака, при этом сверхдоминирование в сторону увеличения признака было у 13,64 \% гибридов.

По содержанию волокна у большинства гибридов $\mathrm{F}_{1}$ наследование признака было по типу промежуточного наследования, доминирования и сверхдоминирования в сторону уменьшения признака. Во втором поколении наблюдался разнонаправленный характер наследования признака.

По содержанию масла 48 \% гибридов $\mathrm{F}_{2}$ проявили сверхдоминирова- 
ние в сторону уменьшения признака, около $24 \%$ - доминирование и сверхдоминирование в сторону увеличения признака, остальные демонстрировали промежуточный характер наследования.

Таким образом, анализируя проявление гетерозиса у $\mathrm{F}_{1}$ и $\mathrm{F}_{2}$ гибридов льна, его более частое проявление выявлено по признаку «масса 1000 семян». Характер наследование этого признака у гибридов $\mathrm{F}_{1}$ и $\mathrm{F}_{2}$ был достаточно стабильным. Наиболее частым проявлением значений признаков «техническая длина стебля» и «содержание волокна» у $\mathrm{F}_{1}$ было доминирование и сверхдоминирование в сторону уменьшения признака, у $\mathrm{F}_{2}$ - разнонаправленный характер наследования. Наследование признака «содержание масла» у гибридов $\mathrm{F}_{2}$ был по типу промежуточного наследования и сверхдоминирования в сторону уменьшения признаков.

\section{Список литературь}

1. Тарутина Л.А. Изменчивость эффекта гетерозиса у диаллельных гибридов кукурузы в различных условиях среды / Л.А. Тарутина, Л.В. Хотылева, Л.М. Полонецкая, И.Б. Капуста // Изменчивость и отбор. Минск. - 1980. - С. 20-28.

2. Брюбейкер Дж. Л. Сельскохозяйственная генетика. - М.: Колос, 1966. - 224 с.

3. Жученко А.А. Экологическая генетика культурных растений (адаптация, реком-биногенез, агробиоценоз). - Кишинев, «Штиинца», 1980. - 588 с.

DOI 10.18699/GPB2020-95

\section{О достижениях селекции и биотехнологии картофеля в Таджикистане}

Нихмонов И.С., н.с.; Гулов М.К., к.б.н., докторант; Партоев К. *, д.с.-х.н., профессор.

Институт ботаники, физиологии и генетики растений АН Республики Таджикистан, г. Душанбе, Таджикистан.

*e-mail:pkurbonali@mail.ru

В условиях Таджикистана в течение более 20 лет балгодаря сочетанию методов традиционной селекции и современной биотехнологии получены новые перспективные сорта и гибриды картофеля. Для повышения эффективности селекционно-семеноводческой работы в будущем особая роль принадлежит комплексному сочетанию традиционных методов селекции картофеля с методами биотехнологии. Благодаря сочетению этих методов создан новый сорт картофеля «Таджикистан», который с гектра дает по 35-40 тонн урожая клубней, что на 40-60\% больше по сравнению со стандартным сортом - «Кардинал» и другими сортами картофеля. Новый сорт картофеля - «Таджикистан» сейчас выращчивается на площуади более 3000 га в разных картофелеводческих хозяйствах республики. 